\title{
Examination of Capacity and Ramping Impacts of Wind Energy on Power Systems
}

Technical Report NREL/TP-500-42872 July 2008

B. Kirby

American Wind Energy Association

M. Milligan

National Renewable Energy Laboratory

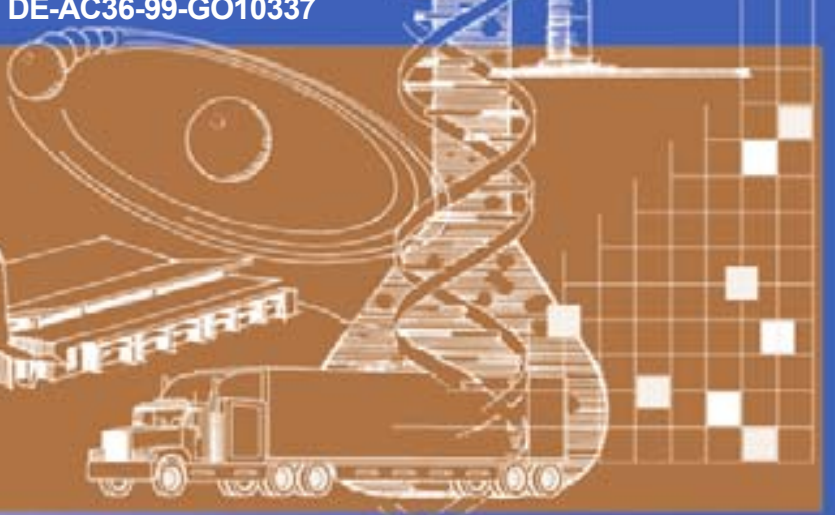




\section{Examination of Capacity and Ramping Impacts of Wind Energy on Power Systems}

Technical Report NREL/TP-500-42872 July 2008

B. Kirby

American Wind Energy Association

M. Milligan

National Renewable Energy Laboratory

Prepared under Task No. WER8.5001

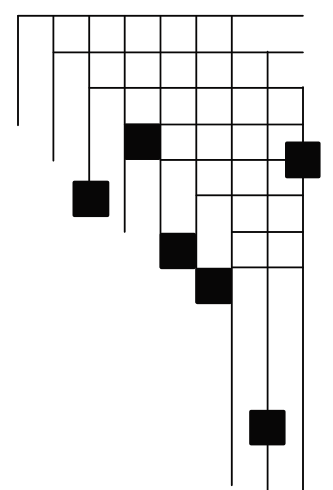




\section{NOTICE}

This report was prepared as an account of work sponsored by an agency of the United States government. Neither the United States government nor any agency thereof, nor any of their employees, makes any warranty, express or implied, or assumes any legal liability or responsibility for the accuracy, completeness, or usefulness of any information, apparatus, product, or process disclosed, or represents that its use would not infringe privately owned rights. Reference herein to any specific commercial product, process, or service by trade name, trademark, manufacturer, or otherwise does not necessarily constitute or imply its endorsement, recommendation, or favoring by the United States government or any agency thereof. The views and opinions of authors expressed herein do not necessarily state or reflect those of the United States government or any agency thereof.

Available electronically at http://www.osti.gov/bridge

Available for a processing fee to U.S. Department of Energy and its contractors, in paper, from:

U.S. Department of Energy

Office of Scientific and Technical Information

P.O. Box 62

Oak Ridge, TN 37831-0062

phone: 865.576 .8401

fax: 865.576 .5728

email: mailto:reports@adonis.osti.gov

Available for sale to the public, in paper, from:

U.S. Department of Commerce

National Technical Information Service

5285 Port Royal Road

Springfield, VA 22161

phone: 800.553 .6847

fax: 703.605.6900

email: orders@ntis.fedworld.gov

online ordering: http://www.ntis.gov/ordering.htm 


\title{
An Examination of Capacity and Ramping Impacts of Wind Energy on Power Systems
}

\author{
Brendan Kirby, Consultant \\ American Wind Energy Association \\ Michael Milligan \\ National Renewable Energy Laboratory
}

\section{Abstract}

When wind power plants serve load within the host balancing area, there is no additional capacity that is required to integrate wind power into the system. The wind energy displaces conventional generators' energy, which may result in emission and fuel savings, or make it possible to sell additional energy to other customers outside the balancing area. This provides a benefit to the sellers and customers. When wind serves load outside of the host balancing area, there can be additional capacity requirements, but these will depend in part on the length of the market period: faster markets will mitigate this requirement, whereas slower markets will exacerbate this capacity requirement. We develop a series of very simple thought experiments to illustrate and discuss some implications for wind integration studies.

\section{Introduction}

There has been considerable work in recent years on wind integration impacts and costs. Most of these studies have featured some combination of statistical analysis on load and wind data, along with detailed system simulations of at least one year, using hourly data. A common finding among the studies is a need for increased operating reserve to help cover the additional variability that wind brings to the system. In most cases, however, this operating reserve is not rigorously defined, which has lead, we believe, to some fundamental misunderstanding of how wind, load, and reserves interact. The erroneous belief is that wind consumes system capacity. In fact, during discussions that we were involved with as part of the Northwest Wind Integration Action Plan (NWIAP), the opinion was expressed that wind likely has a negative capacity value.

These misunderstandings arise from inconsistent use of the term 'capacity' and about the relationship to ramping requirements in systems with significant wind penetrations. In our view, another source of confusion is that wind is often compared to base-load generation as the "neutral" comparison case. We argue that this is the wrong comparative case, and that this source of confusion can distort the measurements of wind's value and costs. In an attempt to help clarify these issues, we develop several simple 'thought experiments' that are designed to focus on the characteristics of wind and its impact on 
system balance. To keep the exposition simple, we do not use real data, although our results can easily be extended to apply to real systems with real data.

\section{Wind Serving Loads within the Host Balancing Area}

The starting point for our analysis is the assumption that wind energy is introduced into a power system that can already meet its load obligations, and the wind will be used within the balancing area (BA). (We will relax this assumption in a later section of this paper.) This assumption has several implications. First, there is sufficient capacity (installed generation) to meet the system peak load plus a reserve margin. Wind's primary value is in saving fuel (or water). If the non-wind generation could meet the load without depending on wind energy, then the load can be met after wind is added to the system. Second, load ramps can be met and balanced by the existing generator fleet; there is sufficient ramping capability over all relevant time scales from seconds, minutes to hours or longer for the existing non-wind system. Note that we have not assumed anything about the ramp requirements of the system once wind has been added to the system; that will be discussed shortly. Third, there is sufficient energy to satisfy customer demand without depending on the wind energy.

Figure 1 illustrates a simple case of a flat load and the required generation. In this simple case we do not consider reserve requirements: the installed capacity curve is offset from the load curve just enough so that both can be seen.

\section{Capacity to Serve Flat Load}

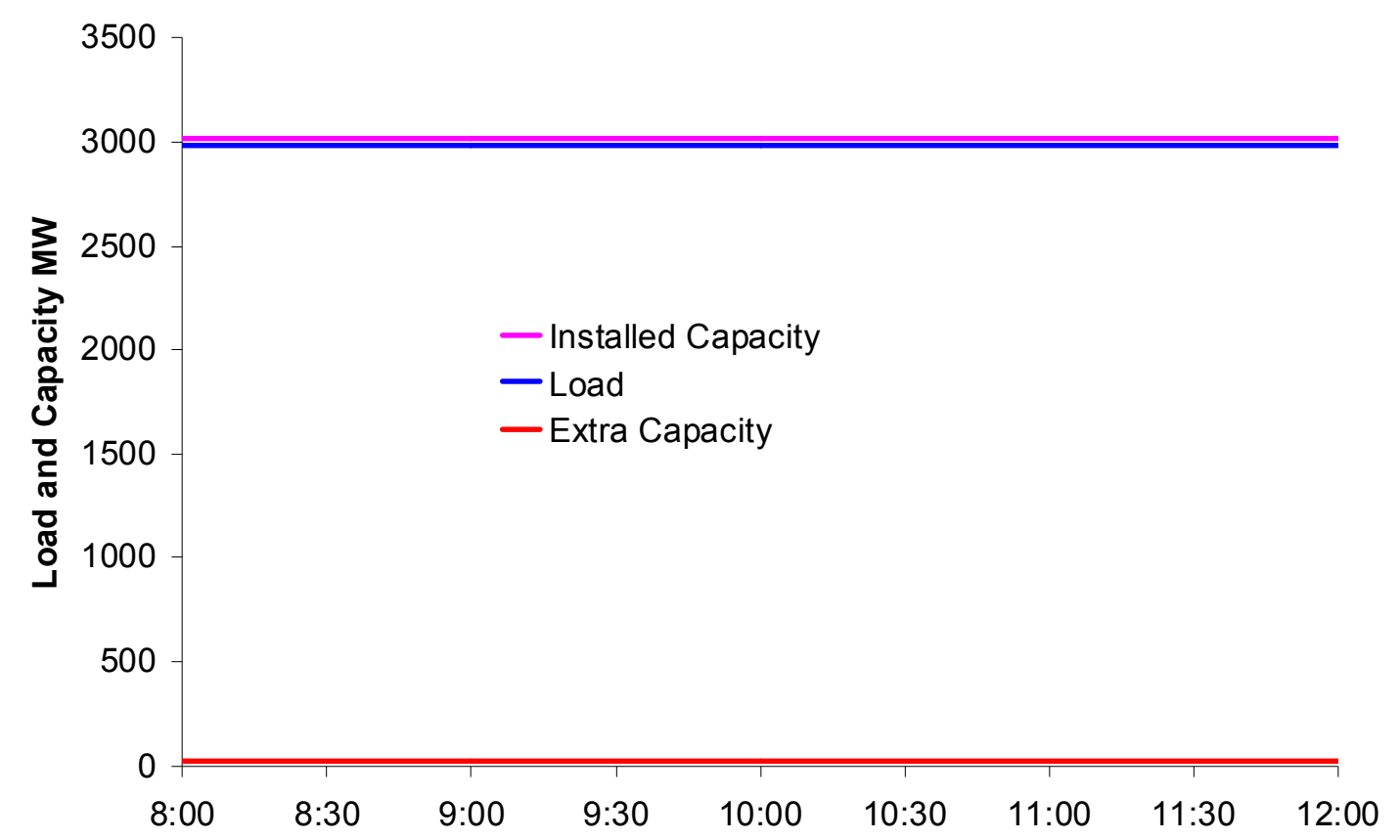

Figure 1 - Flat load requires enough installed capacity to cover load. 
Because there is load variability minute to minute, Figure 2 shows that there must be sufficient generation to cover the maximum load, taking into account the short-term variability. Because the maximum load will exceed the average load for the period, the average load plus the maximum of the regulation impact must be covered by the available generating capacity. This regulating reserve does require more capacity than the flat load. Wind will generally increase this regulation requirement modestly and will therefore have an impact on minute-to-minute regulating capacity requirements. Because we wish to investigate wind's impact on ramping requirements, as distinct from the minute-tominute regulation variability, and to keep the examples simple and clear, we will remove the minute-to-minute variability for the present.

\section{Capacity to Serve Varying Load}

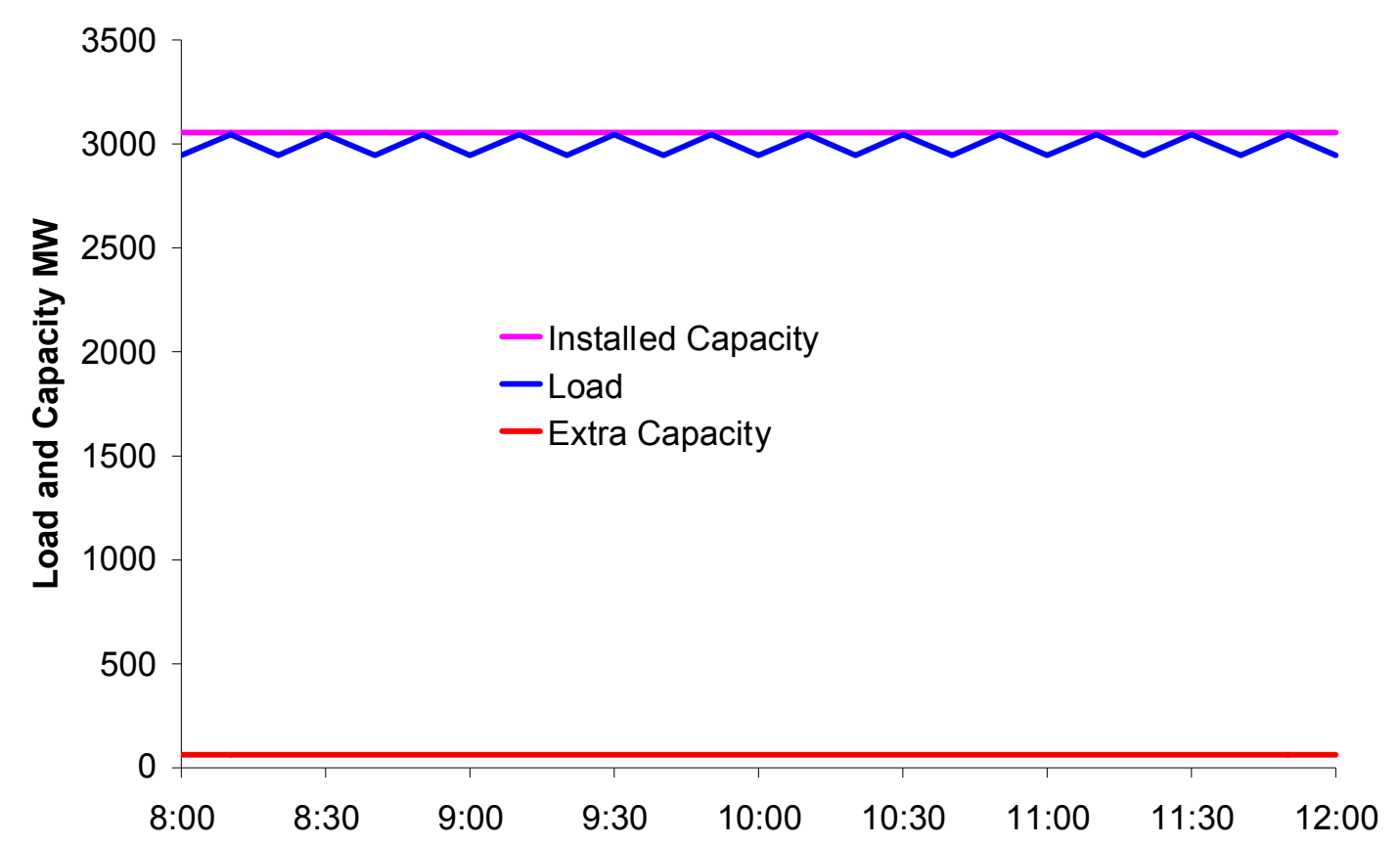

Figure 2 - Minute-to-minute regulation requires additional capacity.

Intera- and inter-hour ramping requirements are much greater than minute-to-minute regulation requirements, but the characteristics are different. Figure 3 shows the impact of the morning load ramp. For simplicity in the graph and for the example, we have dropped the regulation reserves, but of course there is still a need for that. What is apparent from the graph is that there is no need for additional capacity to provide for the load ramp. Capacity that will be used to supply energy from 10:00 to 12:00 is available to follow the 9:00 to 10:00 ramp because it was not supplying energy before 9:00. 
Additional movement is required from the existing capacity so that the system remains in balance, but no additional capacity is required beyond what is needed to meet the peak hour energy requirement.

We now create a simple scenario with constant load and variable wind. For this example, we assume that wind energy is only produced from 8:00-10:00, and hold the load constant. Figure 4 shows $500 \mathrm{MW}$ wind output from 8:00-9:00, ramping down from 9:00-10:00. The wind energy delays the need for $500 \mathrm{MW}$ of other generation until 9:00, at which time the wind begins to reduce its output, causing a need for an offsetting increase in the other generation. From 10:00-12:00 the conventional generation is positioned exactly where it was in the no-wind case. From 8:00-9:00 there is a reduction in the conventional capacity required compared to the no-wind case, and this reduction is gradually reduced from 9:00-10:00, but there is never an increase in conventional generation capacity above what was already required to serve load.

\section{Capacity to Serve Ramping Load}

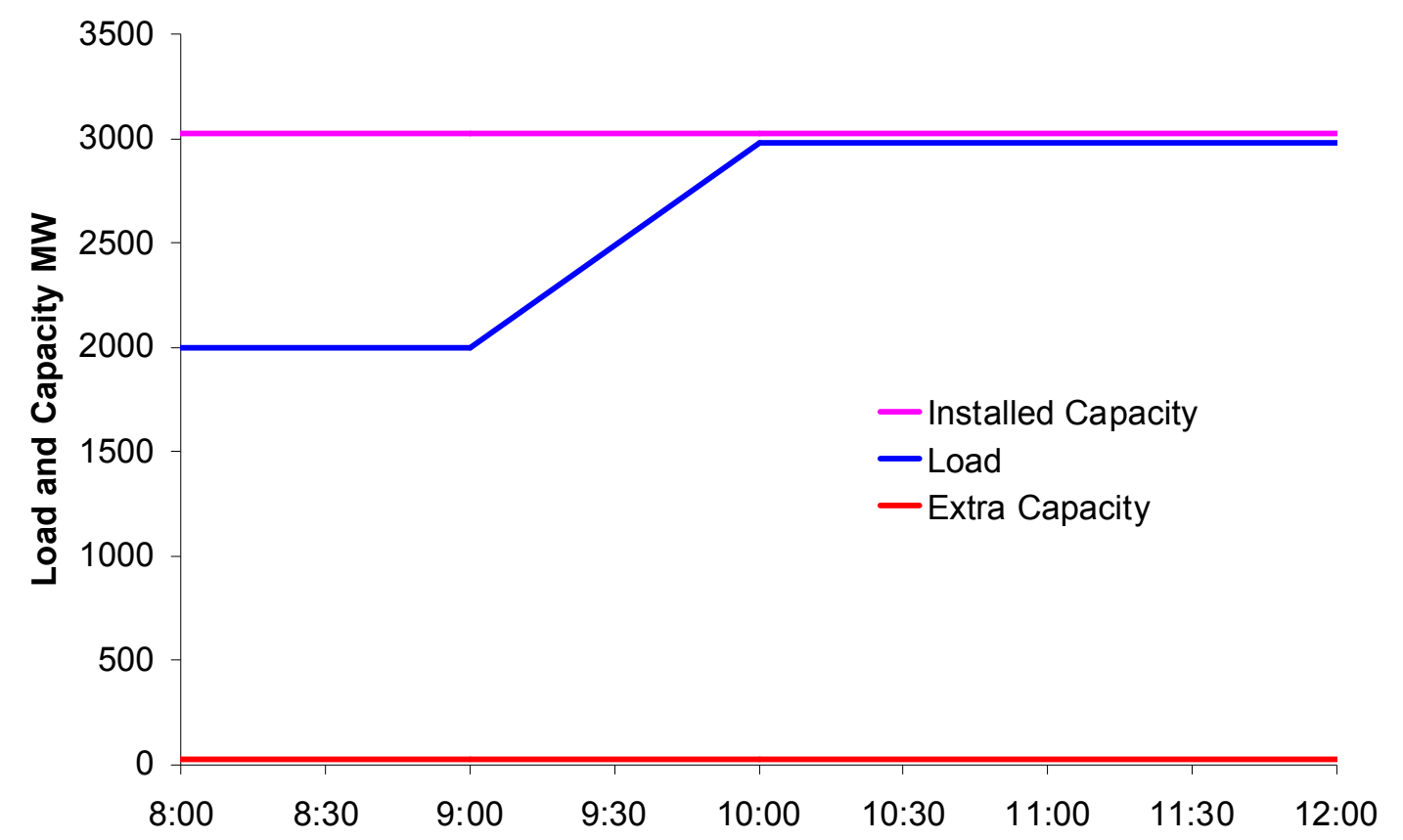

Figure 3 - Load ramps do not require additional capacity, just additional movement of existing capacity. 


\section{Wind Serves Internal BA Load}

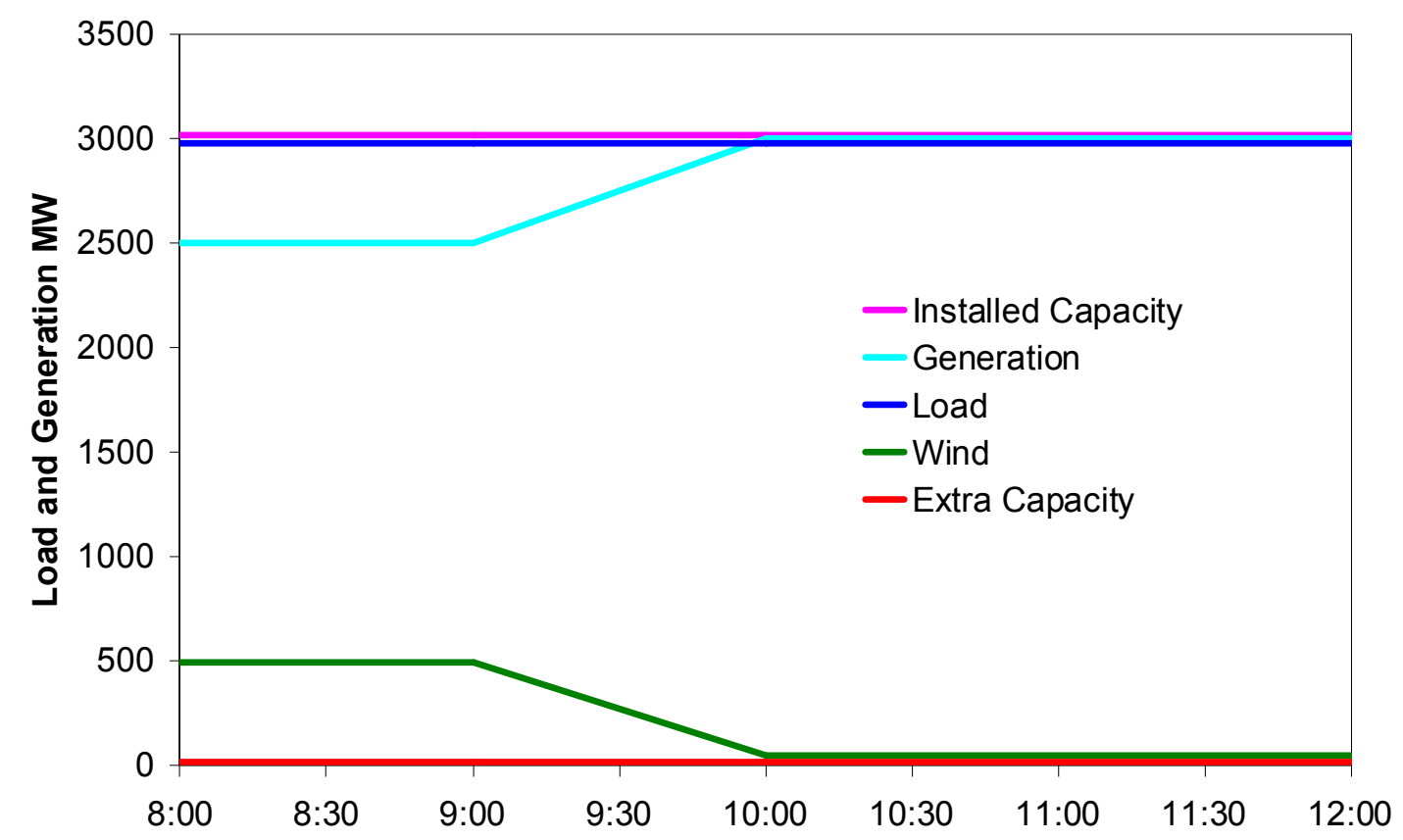

Figure 4 - Wind serving loads within the host BA does not require additional capacity, just additional movement of existing capacity.

Our simplistic graph does not show the variability of the wind during the 8:00-10:00 period. Suppose now that the wind varies between 300-500 MW during the period 8:009:00. In this case, instead of a reduction in conventional generation of $500 \mathrm{MW}$ for the hour, this reduction would vary between 300-500 MW. However, it is clear that there is no need for conventional capacity beyond what is already required for the load.

It is also clear that the addition of wind does not increase capacity requirements when wind is used to serve internal BA loads. Later we will discuss the additional off-system energy sales opportunities created when wind serves internal BA loads, and limitations on those opportunities imposed by imperfect forecasts, but first we will discuss the conceptually simpler case where wind simply serves off-system loads. 


\section{Wind Serving Loads External to the Host Balancing Area (BA)}

In the previous section we showed that when wind is serving load within the host BA, it does not require additional capacity. In this section we show that when wind serves load outside of the host BA, there is an additional capacity requirement. That additional capacity requirement is tied to the nature of transactions between BAs, and is not due to a physical capacity need. We also show that there are institutional mechanisms that can be used to reduce or eliminate this capacity need. For this example, we assume that the region runs hourly dispatch/market schedules for inter-BA transactions. We show how this assumption affects the outcome in a later section of this paper.

Figure 5 illustrates our example. Wind generation in one BA is being delivered to another BA. Just before 9:30, the wind generation drops over a 15-minute period. The region only allows inter-BA schedules to change at the top of each hour, however, so the host BA must continue delivery of the scheduled wind energy from the non-wind fleet until the top of the next hour. In this case, the host BA generation must exceed its load for the duration of the market period; this represents a capacity requirement on the host.

\section{Wind Serves External Load}

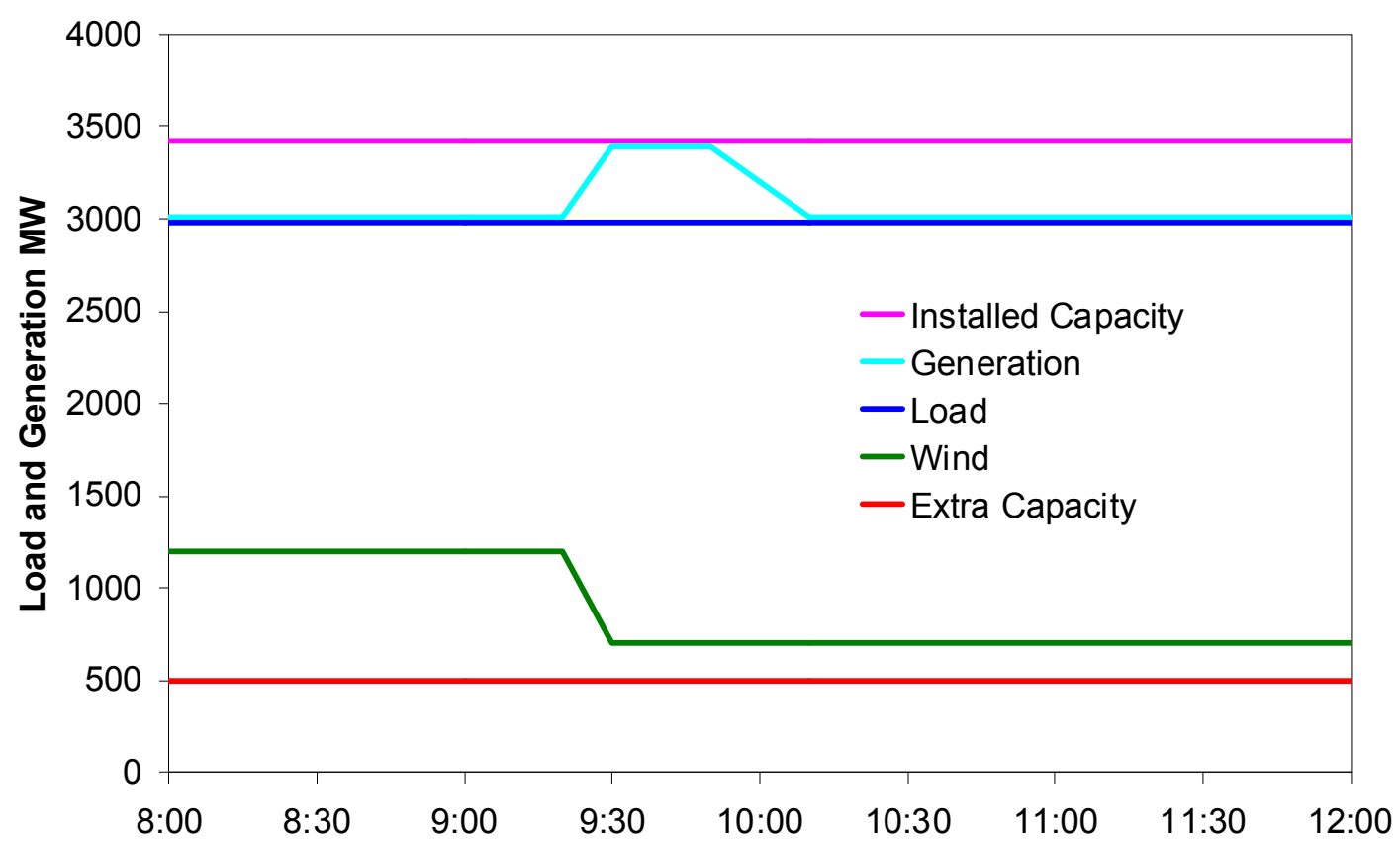

Figure 5 - Wind serving loads outside the host BA does require additional capacity; the host covers the wind delivery until the end of the scheduling period, 1 hour.

Unfortunately, from the point of view of the receiving BA, the capacity used by the host to maintain the wind schedule is of no benefit. The receiver cannot use this capacity, and the only real impact is a delay in response speed for the generators in the receiving BA. This is shown in Figure 6. Because the market period clears hourly, the delivered wind 
power differs from the actual wind power as a result of the host covering the schedule. The receiver does need to respond to the change in wind power, but this response does not happen until the next market period. Therefore, there is a delay in the required response from the receiver, but there is no capacity advantage for the receiver.

\section{External BA Receives Wind}

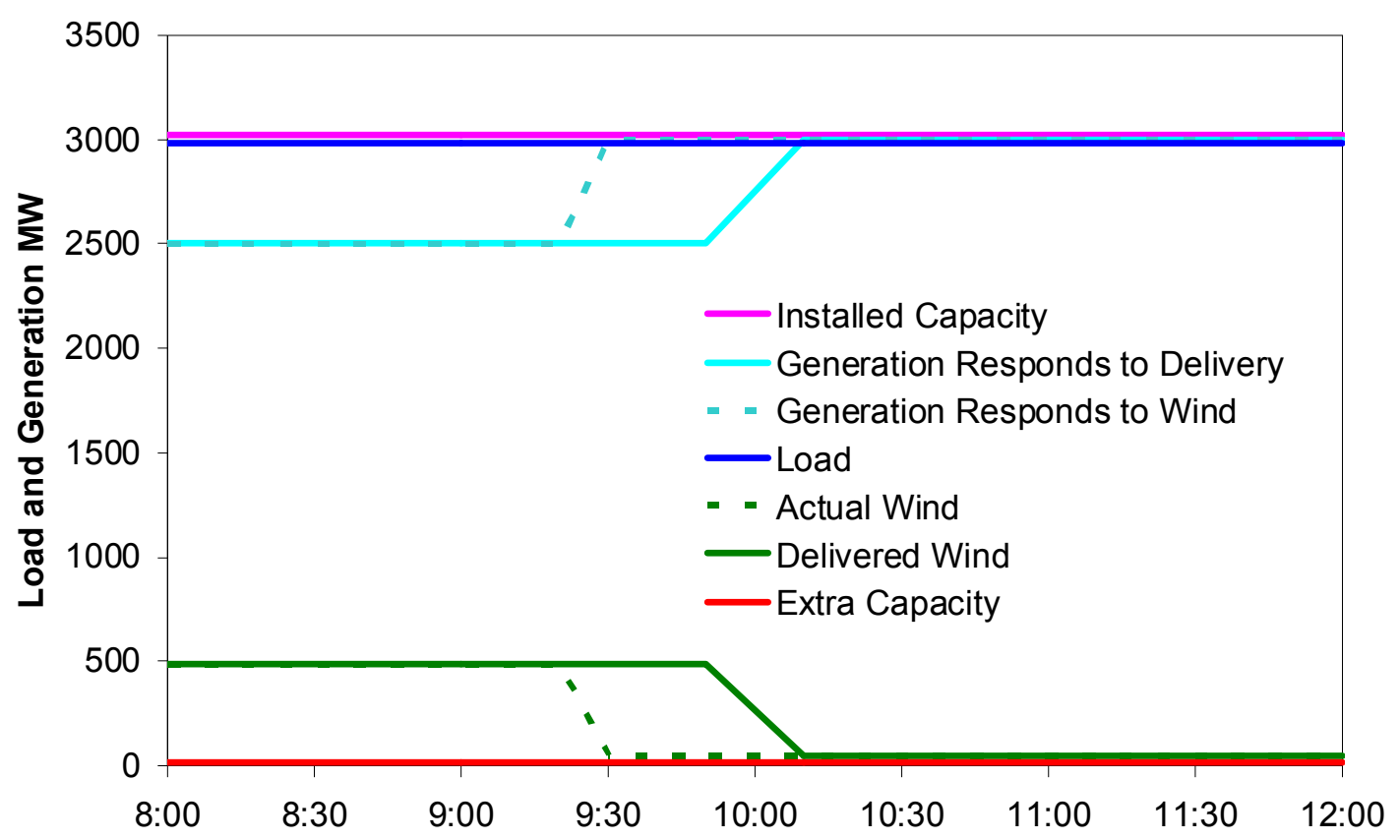

Figure 6 - The BA that receives the wind does not get a capacity benefit, only a delay in response speed. 
The extra capacity requirement on the host can be eliminated if the receiver can rapidly respond to the change in wind output. This can be accomplished by several means, and will be discussed below. Figure 7 shows the impact on both BAs. When the wind output falls, as shown in the left panel of the figure, the host does not need to respond because the receiver does. In the right side of the figure, the dotted line shows the delayed response from the previous case that is no longer required. Instead, the receiver increases generation as the wind drops off. It seems clear from this example that the excess capacity need can be eliminated if the receiver has a way to quickly respond to the wind. ${ }^{1}$

This can be accomplished in several ways:

- a dynamic schedule or pseudo-tie that dynamically moves the wind generation to the receiver's BA

- faster market-clearing periods

- bi-lateral agreement between the BA

- combined operation of the two BAs.
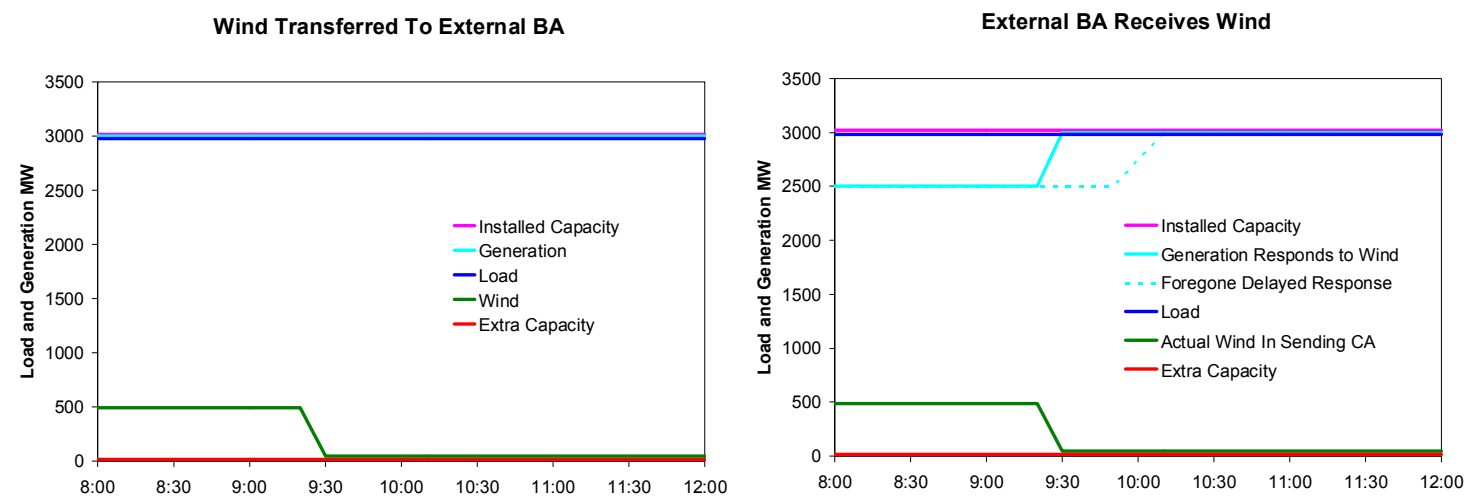

Figure 7 - No additional capacity is required if the receiving (external) $B A$ responds when the wind drops.

\footnotetext{
${ }^{1}$ The receiving area response requirement may in fact be easier to meet when it is responding directly to changes in the wind. This is because inter-BA schedule changes occur over 20 minutes (10 minutes in the east) while the wind ramp may be moving at a slower rate.
} 
While a full dynamic schedule or pseudo-tie can be used to essentially move a wind generator (or any generator) from the physical host BA to the BA with the load it is serving, this is not always necessary. Providing a means to adjust inter-BA schedules every five to fifteen minutes may be simpler, cheaper, and more flexible in many cases.

\section{Wind-Created Off-System Sales Opportunities}

So far, we have seen that no additional capacity is required when wind is used to serve load within the host BA. We have also seen that no additional capacity is required when wind serves load in an adjacent BA if the inter-BA schedules can be adjusted within the hour. Any additional capacity requirement is an artifact of inter-BA scheduling limitations and provides no real benefit to anyone. It is a true economic inefficiency.

Returning to the example of wind supplying load within the physical host BA examined in section III, we find that the addition of wind may create an opportunity for additional inter-BA sales for the non-wind generators. When wind is supplying load, the displaced non-wind generation is available to supply other loads. For example, if the wind energy can be predicted with certainty (we relax this assumption shortly), this creates the opportunity for increased off-system energy sales from 8:00-9:00, tailing off from 9:0010:00 as shown in Figure 8. This energy sale from the existing conventional generation is

made possible by the wind, because without the wind, the conventional generation would be needed to serve the load. 


\section{Wind Serves Internal BA Load}

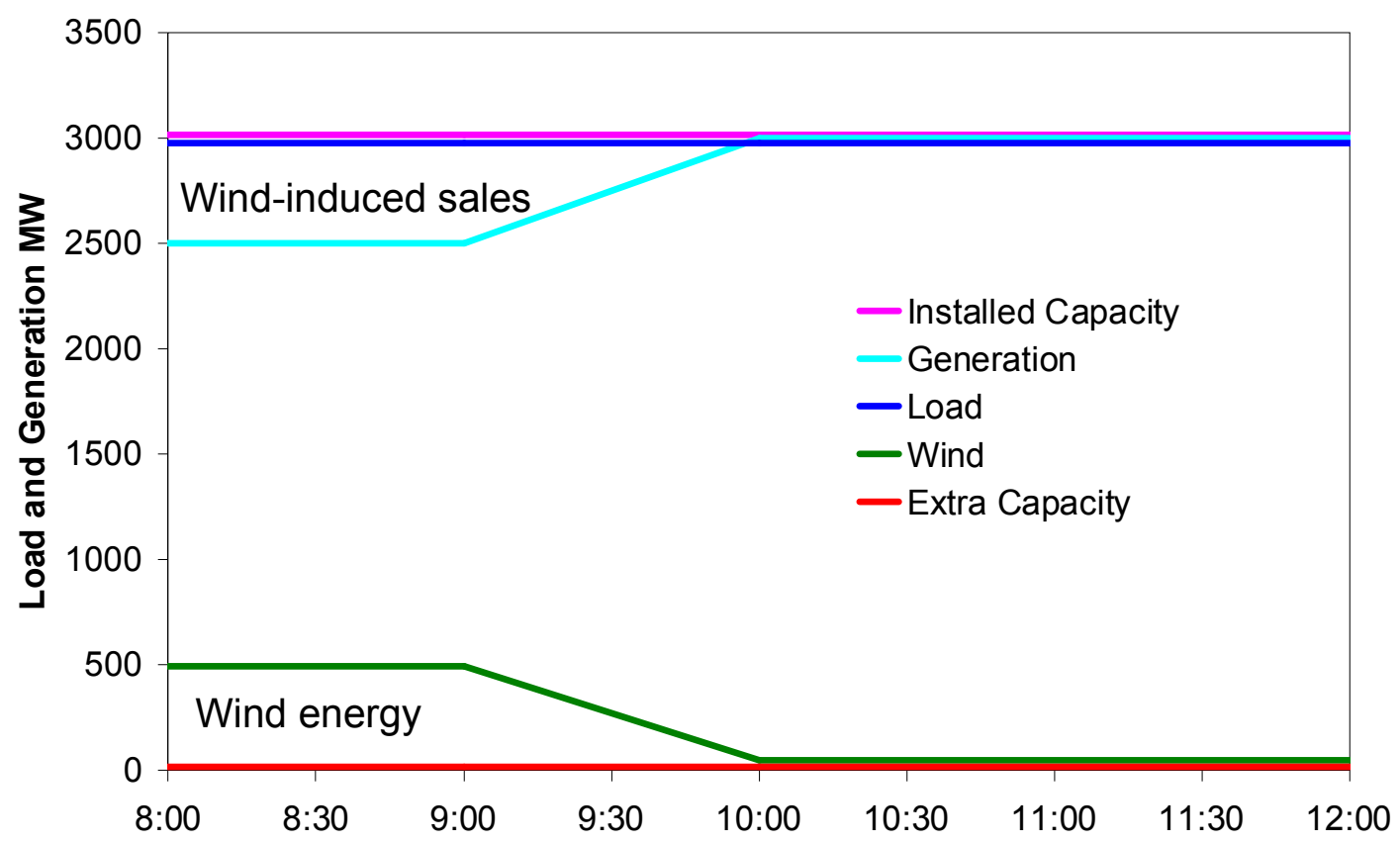

Figure 8 - Wind serving load within the host BA makes it possible for additional energy sales that benefit the BA and its customers.

Imperfect load forecasts, wind forecasts and inter-BA scheduling restrictions create a problem, however (we ignore the impact of load forecast errors in this discussion). As is the case of wind generation in one BA serving load in another BA examined in section IV, the physical host BA may have to continue to supply the scheduled power for the remainder of the hour even if the wind drops unexpectedly. This will require additional generating capacity, similar to that shown in Figure 5. Is this an additional capacity requirement imposed by wind? No. It is a limitation on the additional off-system sales opportunity created by the wind.

Because wind forecasts are not perfect, it is likely that the system operator would not want to enter in to a firm off-system sale for all of the wind energy, allowing for some forecast error. To retain the simplicity of our analysis, we assume that some fraction of the wind forecast will be sold in the forward market, leaving some additional wind that could be sold in the real-time imbalance market. We arbitrarily divide the sale made possible by wind geometrically in half for illustration. As shown in Figure 9, the addition of a wind forecast error does not increase the capacity needs of the BA compared to the no-wind case. Because the actual wind is the same as in the previous case, the required physical response is also the same. However, forecast error does impact the nature of the off-system energy sales opportunity which the addition of wind creates. Based on the risk preferences of the system operator, the characteristics of the units on the dispatch stack, and the expected wind forecast error, there could be a difference in the way that the system is positioned going in to the operating hour. 


\section{Wind Serves Internal BA Load}

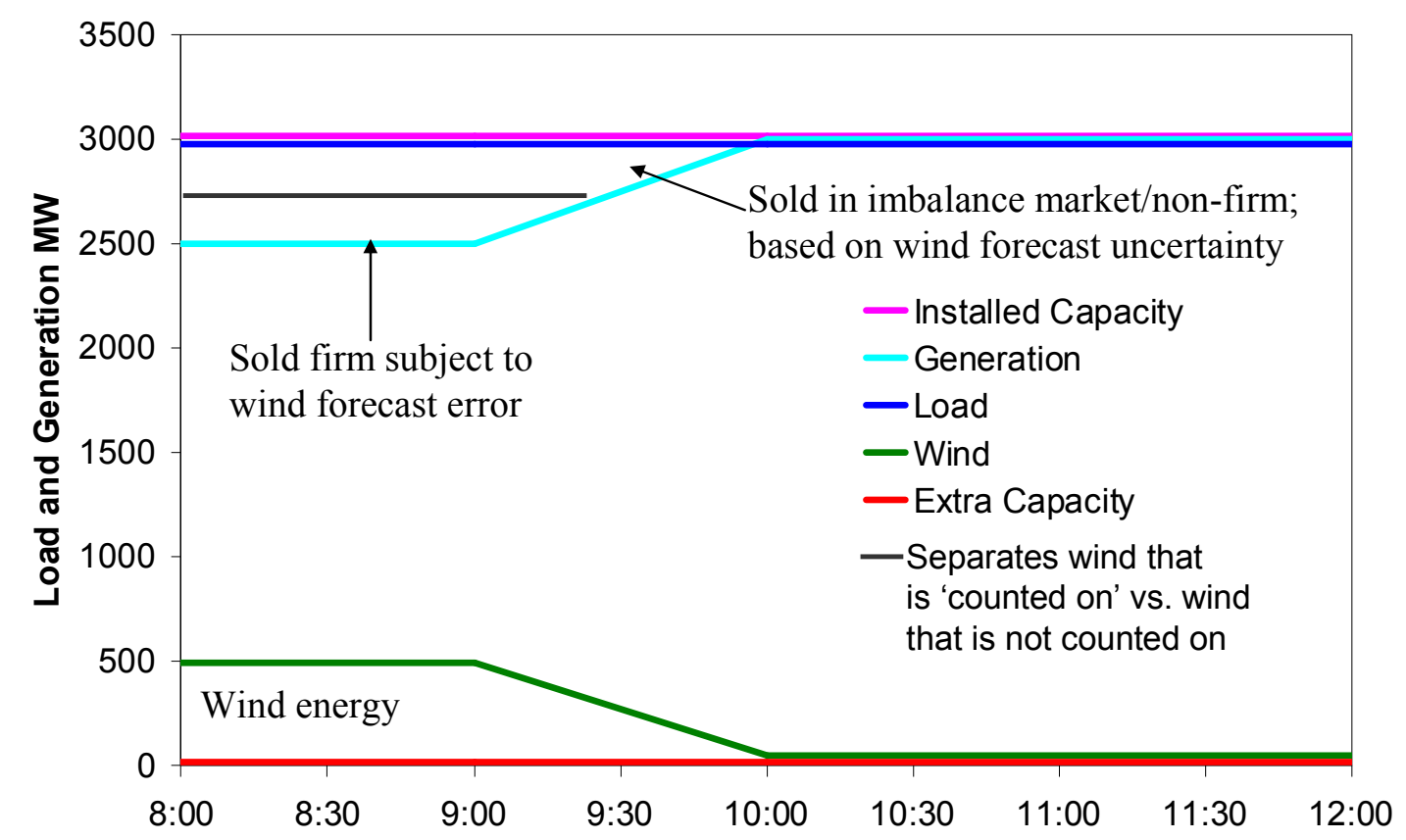

Figure 9 - The amount of wind-induced energy sold may be less than the total wind energy based on wind forecast uncertainty.

In systems that have significant controllable hydro, for example, it may be possible to significantly reduce or eliminate the uncertainty of the wind forecast. The hydro system could potentially be used to store the wind energy for 2 hours before re-delivering it. Because the wind generation would then be known with certainty, the split between a firm and non-firm sale such as shown in Figure 9 would not be relevant because all wind could be sold as firm.

\section{Load Following As a Byproduct of Fast Energy Markets or the Economic Dispatch Stack}

When wind is providing energy to its native BA, we have shown that there is no need for additional capacity, relative to the no-wind case. It is clear that wind will likely impose additional ramping requirements on the system. Before discussing the impact of wind on ramping in more detail, we first examine the relationship between load following and energy markets. Our discussion can easily be applied to vertically integrated utilities that practice economic dispatch, however, for the discussion we focus on the case of an open energy market. 
To sell energy into a market, it is necessary for the generator to be maneuvered to the appropriate level of output. Base-load units are typically not required to maneuver much as they supply energy. The unit commitment process selects the unit for operation; the unit is started and brought to its rated capacity over a period of hours. The low operating cost of base-load units (below the market clearing price) allows them to participate in energy markets by continuously operating at their full economic output.

Intermediate and peaking units operate differently. Their somewhat higher operating cost is not always below the energy market clearing price so they do not participate in the market unless the clearing price is at or above their cost of generation. These units may not run at night when prices are low, for example, but instead operate and sell energy during the day. In order to sell into a given hourly market, the intermediate unit must position itself so that it can sell the prescribed energy for the duration of the market period. In subsequent market periods, the generator must again move to a new output level if it will sell more or less energy than in the first period, depending on its operating cost and the market clearing price. Failure to respond to market prices seriously hurts an intermediate unit. The unit incurs a lost opportunity if the market price is high and it does not turn on and ramp up to sell. Similarly, the intermediate unit looses money if the market price is below its operating cost and it does not turn off or minimize production.

Energy markets are able to obtain a great deal of load following response from intermediate and peaking generators without explicitly paying for it. This is very different from regulation where the system operator must purchase a specific regulation ancillary service.

Most of the time the intermediate and peaking units can position themselves as needed, and each interconnection has procedures for allowing for the required ramps so that at the top of the hour, units have achieved their desired level of output. However, there are times when the generators can't move quickly enough, which results in very high energy prices for a short duration of time. This situation can arise if the dispatch stack is not sufficiently deep or if sufficient ramping capability does not exist. Figure 10 shows an example of a base-load unit that is on the margin that is unable to ramp quickly enough between 8:30 and 9:00 to meet the load, which ramps quickly during this time. Instead, fast maneuverable generation, such as a peaking unit with very high marginal cost, must be dispatched to cover the ramp. Once the base-load unit catches up to the load, the peaking unit is no longer needed. If the energy price is set based on the marginal unit, the price will rise from $\$ 10.00 / \mathrm{MWh}$ at $8: 30$ to $\$ 90 / \mathrm{MWh}$ from $8: 30-12: 30$, and then fall back to $\$ 10 / \mathrm{MWh}$. In this case, the price spikes because the marginal generator is not nimble enough to fully participate in the energy market starting at 9:00. 


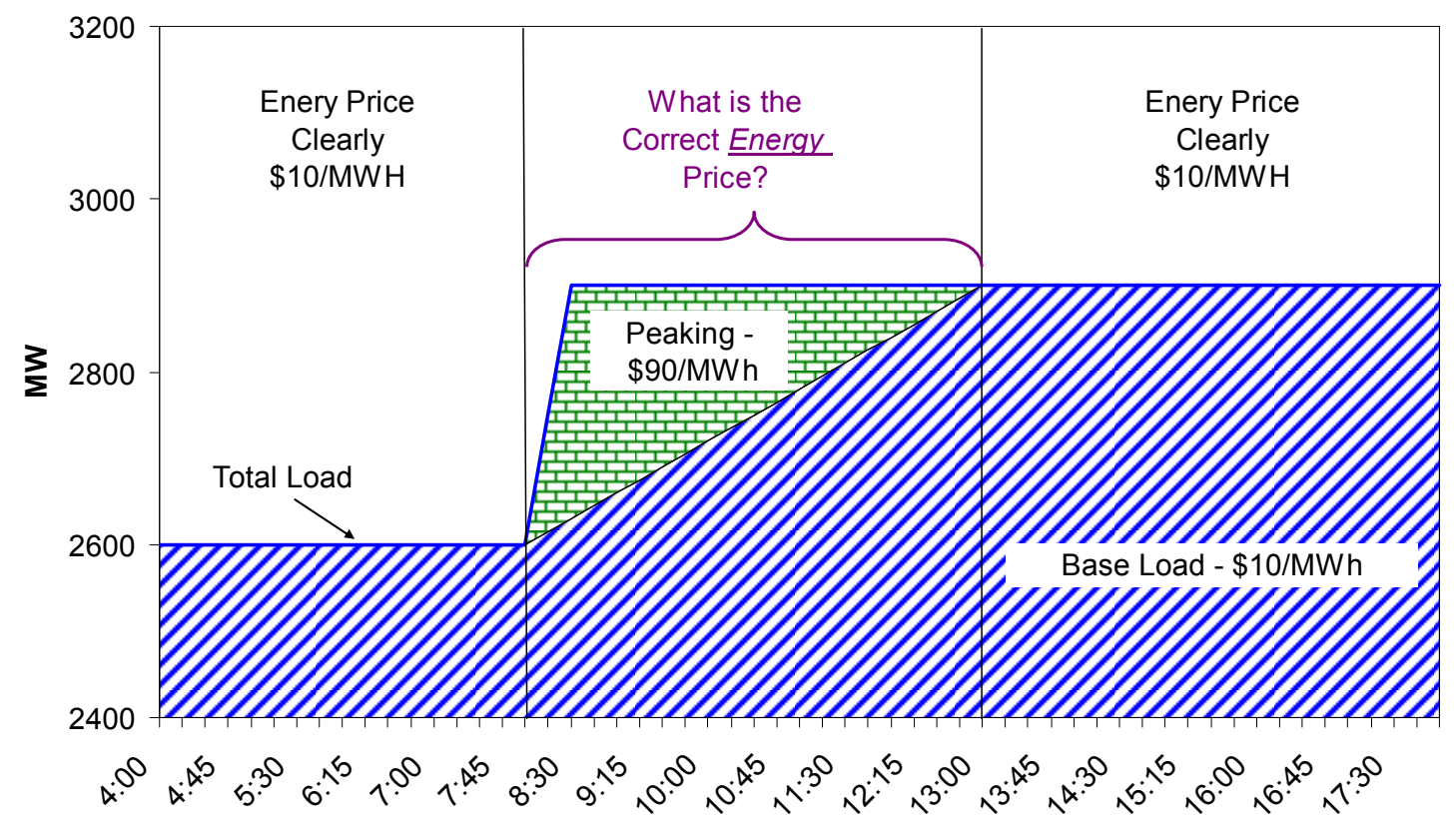

Figure 10 - Load following is a distinct service that is needed if ramping capability impacts the energy market unit selection.

Conversely, if the load had followed the capability of the base-load unit, the required load following would have simply been extracted from the energy market. The generator would have been able to position itself to provide energy for load, and no distinct load following service would have been needed.

Introducing wind into the example, Figure 11 shows that the ramp requirement may increase further. We have purposely provided a challenging case; the solid line shows the net load after wind energy is applied to the needed load. At 5:30, wind generation increases, which in turn decreases the capacity and energy required from the base-load unit. At 6:30, the wind reaches its maximum generation level, and remains there until $8: 30$, at which time the wind falls off quickly. 


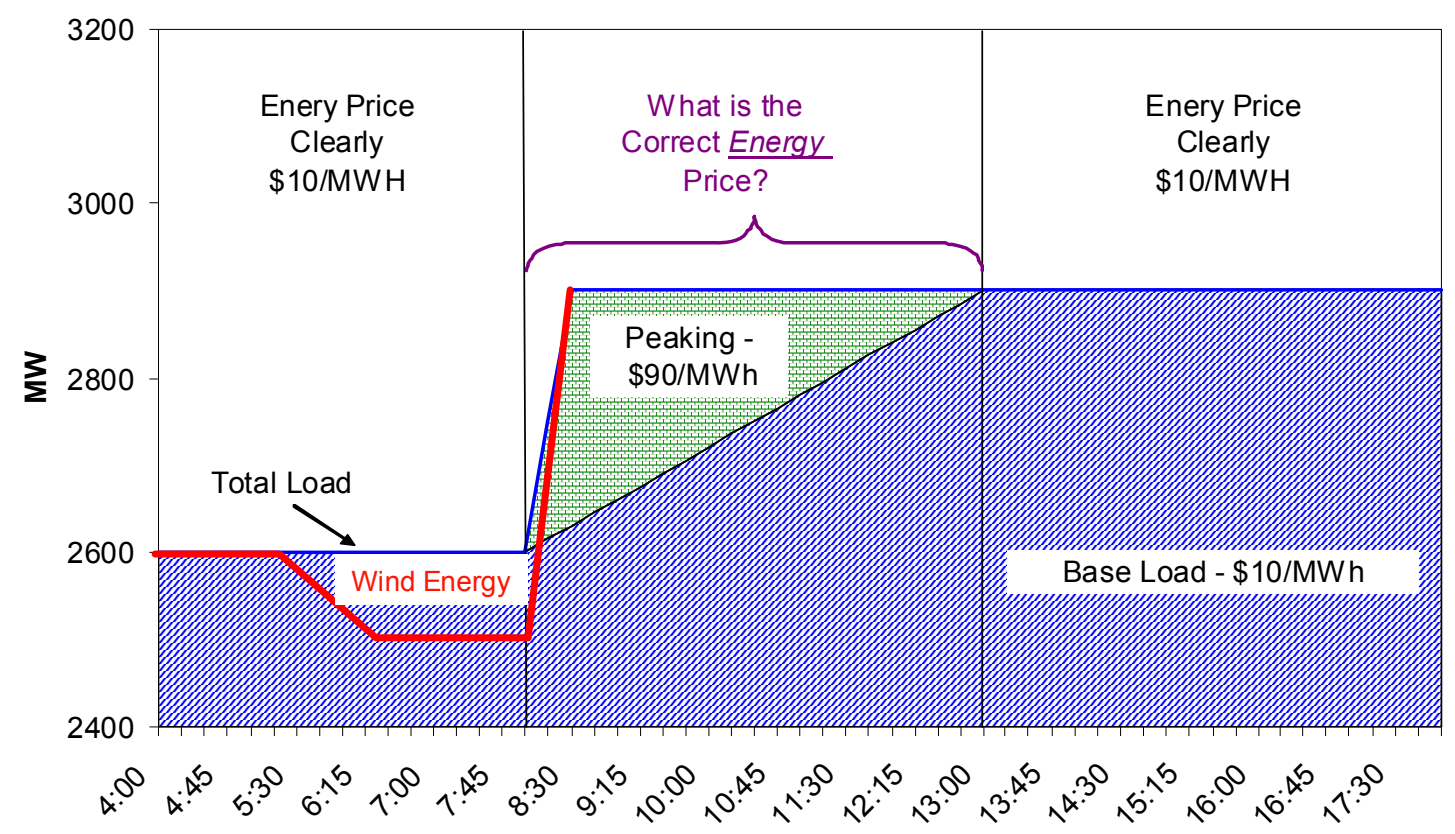

Figure 11 - Wind energy can increase ramping requirements and provides additional energy, but does not require more capacity.

When the wind picks up at 5:30, the base-load generation reduces its output. Although in our example we assume that there is sufficient downward flexibility, this need not be the case. When the wind begins to reduce output at 8:30, the ramp requirement is even steeper than in the no-wind case, which required a peaking unit to pick up the ramp. Clearly, in this example, wind has increased the need for load following and additional peaking capacity (or other fast-ramping unit) is required to maintain system balance.

In this example, no additional capacity is needed to maintain system balance. The wind reduces the conventional capacity usage from 5:30-9:00 and imposes an additional downward ramp requirement on the base unit. Wind further exacerbates the ramping shortfall from 8:30-9:00, but does not require additional capacity. Instead, wind imposes a need for more flexible capacity. If that flexibility cannot be provided from the energy market, it must be provided by a load following market or by emergency provisions.

\section{Market Evidence from New York Independent System Operator (NYISO) Data}

Existing energy markets provide evidence that load following can be provided by energy market movements. Clearly, all hourly markets follow the rise and fall in generation required to match the daily load pattern without resorting to a special load-following charge. Energy prices during the afternoon are simply higher than energy prices in the middle of the night. Data from sub-hourly energy markets show that faster generator 
response is also provided from energy markets without resorting to a special loadfollowing charge.

An examination of sub-hourly energy markets shows that the energy markets themselves provide an incentive for generators to respond to power system needs for movement, and they do it without incurring costs to customers. ERCOT, PJM, NYISO, ISONE, MISO, and $\mathrm{CAISO}^{2}$ all operate sub-hourly energy markets which are capable of responding to wind and load variability, and forecast error. We examined a year of sub-hourly price data from NYISO.

Examination of price data from the NYISO 5-minute real-time market provides insights into how load following can be extracted from sub-hourly energy markets at little or no cost. NYISO 5-minute real-time energy market price-data was examined for all of 2006 to determine if there is a cost associated with obtaining sub-hourly response from generators. Clearly, obtaining minute-to-minute response is costly since regulation is always the most expensive ancillary service, with prices that remain high even at night. Presumably then, 5-minute response would be more expensive than hourly response. NYISO data provides some surprising results.

Regulation markets specifically procure maneuvering capacity from generators. When a generator sells a MW of capacity to the regulation market for an hour the generator gives the system operator the right to move the generator's real-power output anywhere within the sold range in whatever manner the system operator desires. Generators participating in sub-hourly energy markets, on the other hand, do not sell control; they simply respond to energy price signals. Further, prices seldom go to zero or negative. This means that a generator's response incentive in any given sub-hourly interval depends on the generator's production cost; some generators will have an incentive to respond, and others will not. Any are free to maintain a constant output and accept the hourly average price if their maneuvering cost is too high. Studying a year of 5-minute price data, we found that the NYISO 5-minute market provides a significant response incentive with the high and low prices for each interval in the hour differing by $\$ 17.41 / \mathrm{MWh}$ on average. The market is continuously sending the 5-minute market a strong price signal to move up or down.

Figure 12 presents a simplified twenty minute example. Market prices are shown in the upper part of the graph. The 5-minute market price varies for every interval between $\$ 55 / \mathrm{MWh}$ and $\$ 75 / \mathrm{MWh}$. Clearly, any generator with a production cost below $\$ 55 / \mathrm{MWh}$ will provide full output continuously, and will have no incentive to maneuver because it is making a profit during every interval.

Things are more interesting for a generator with a production cost above $\$ 55 / \mathrm{MWh}$. The lower portion of Figure 12 shows the profit that a generator with a $\$ 60 / \mathrm{MWh}$ production cost would receive from the two behaviors in the market. The generator would earn a

\footnotetext{
${ }^{2}$ Electric Reliability Council of Texas (ERCOT), PJM Interconnection (PJM), Independent System Operator of New England (ISONE), Midwest Independent System Operator (MISO), California Independent System Operator (CAISO)
} 
$\$ 5 / \mathrm{MWh}$ profit if it maintained a constant output $(\$ 65 / \mathrm{MWh}$ average price - $\$ 60 / \mathrm{MWh}$ production cost). It would earn $\$ 7.50 / \mathrm{MWh}$ profit $(\$ 75 / \mathrm{MWh}$ price - $\$ 60 / \mathrm{MWh}$ production cost $=\$ 15 / \mathrm{MWh}$ profit for half of the time and $\$ 0 / \mathrm{MWh}$ for the other half of the time), $\$ 2.50 / \mathrm{MWh}$ more, if it responded to the 5-minute price signal and curtailed production during the intervals that the price was below its production cost (we have a very flexible generator in this simplified illustrative example).

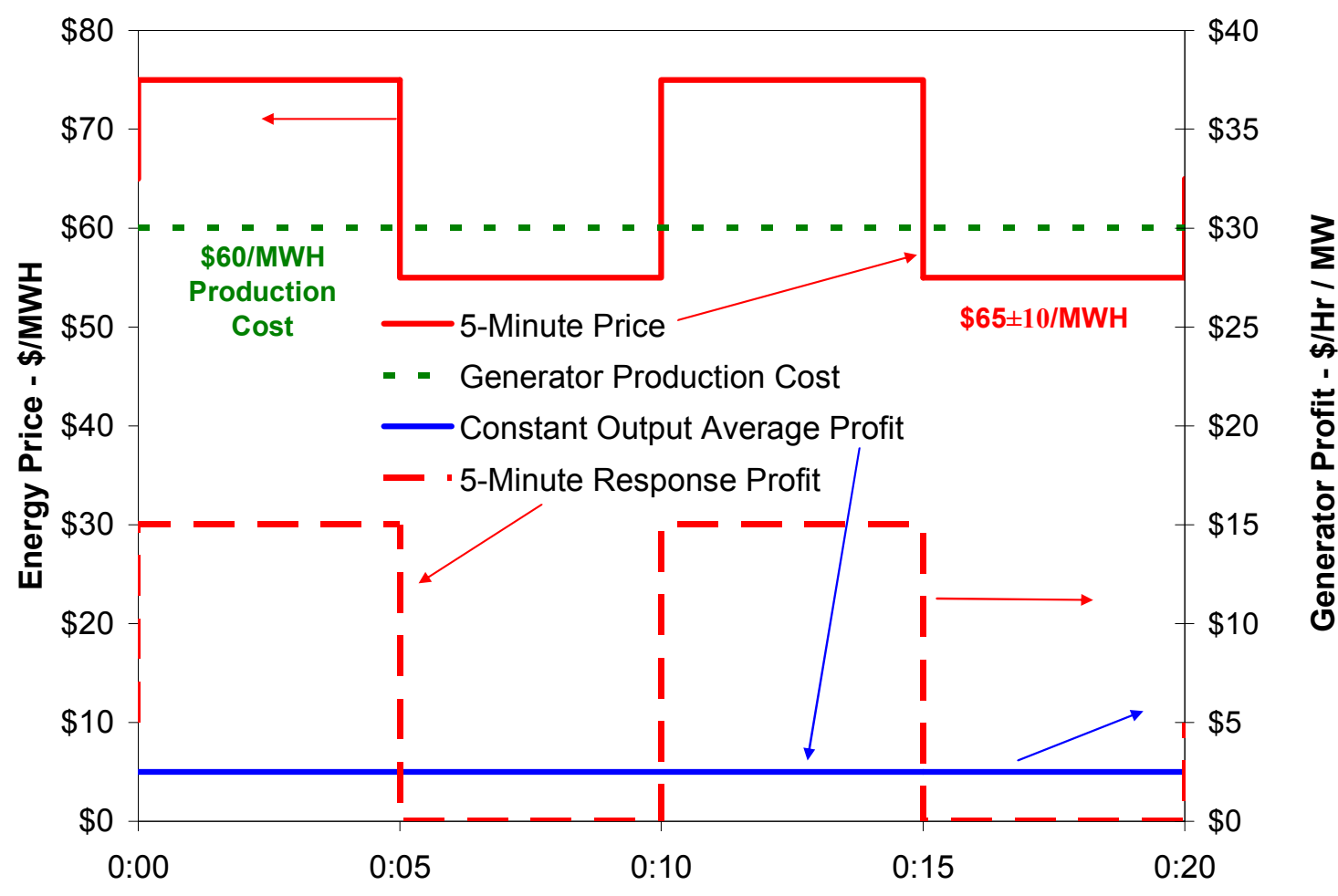

Figure 12 - A simplified twenty-minute example shows there is an incentive for some generators to respond to 5-minute price signals.

The 5-minute market provides an economic incentive for generators with marginal costs that are close to the market clearing price to respond. Figure 13 shows how the incentive to respond (green solid curve) changes as a function of generator production cost, peaking when the production cost is equal to the market prices. Note that while the incentive to respond rises as generator production cost rises, the actual profit the generator receives for either behavior declines (blue dashed and red dotted curves).

The NYISO market provides a real-world example of these price incentives. NYISO operates both 5-minute and hourly real-time markets:

- $\$ 55.51 / \mathrm{MWh}$ average day-ahead hourly price

- $\$ 52.01 / \mathrm{MWh}$ average real-time 5-minute price

- $\$ 3.50 / \mathrm{MWh}$ average fast-market participation penalty. 


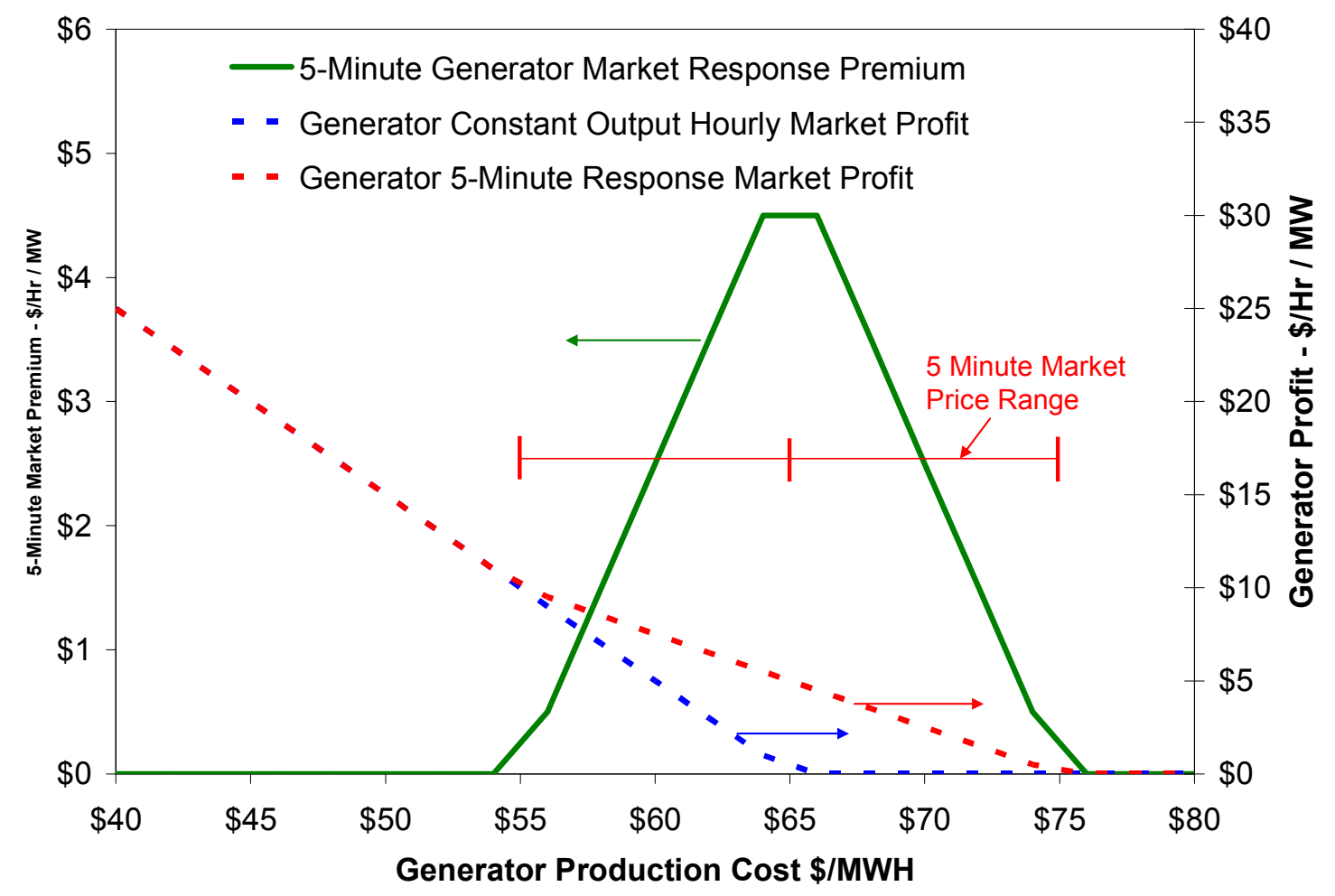

Figure 13 - The sub-hourly response incentive is a function of the generator's marginal production cost.

The average energy price for all of 2006 was $\$ 3.50 / \mathrm{MWh}$ higher in the day-ahead hourly market than in the 5-minute real-time market. This price difference reflects the difference in value of day-ahead commitment vs. the real-time transaction, as well as any difference associated with the faster 5-minute response. This appears to say that there is no overall cost to the power system associated with obtaining 5-minute response from generators; in fact, the faster market clears at a lower price on average.

Given that the hourly market yields a higher average price than the 5-minute market, and given that any unit capable of responding to the 5-minute market is capable of responding to the hourly market (but the opposite is not necessarily true), one wonders why any generator would choose to participate in the 5-minute market instead of the hourly market? One answer lies in a more detailed look at the two markets.

While the annual average prices for the two markets are fairly close, prices during individual 5-minute intervals differ significantly. The annual average of the price difference absolute-value during each 5-minute interval is $\$ 17.41 / \mathrm{MWh}$. The NYISO market is continuously sending the 5-minute market a very strong price signal to move up or down with respect to the hourly market.

Figure 14 presents results from examining potential generator profits achieved when responding to the actual NYISO 5-minute price signals vs. providing constant output throughout the hour for all of 2006. The response incentive is negative for generators 
with a production cost below $\$ 40$ because the day-ahead hourly market has a higher average price than the five-minute market. A generator that will not be better off in the five-minute market will be committed to the day-ahead market. A generator with a production cost above about $\$ 40 / \mathrm{MWh}^{3}$, however, has an incentive to respond to the 5minute market price signals. Of course, any actual generator will move between the two markets throughout the year as price signals dictate. The incentive to respond is higher for high-cost generators, both in absolute dollars and as a percentage of their total profit.

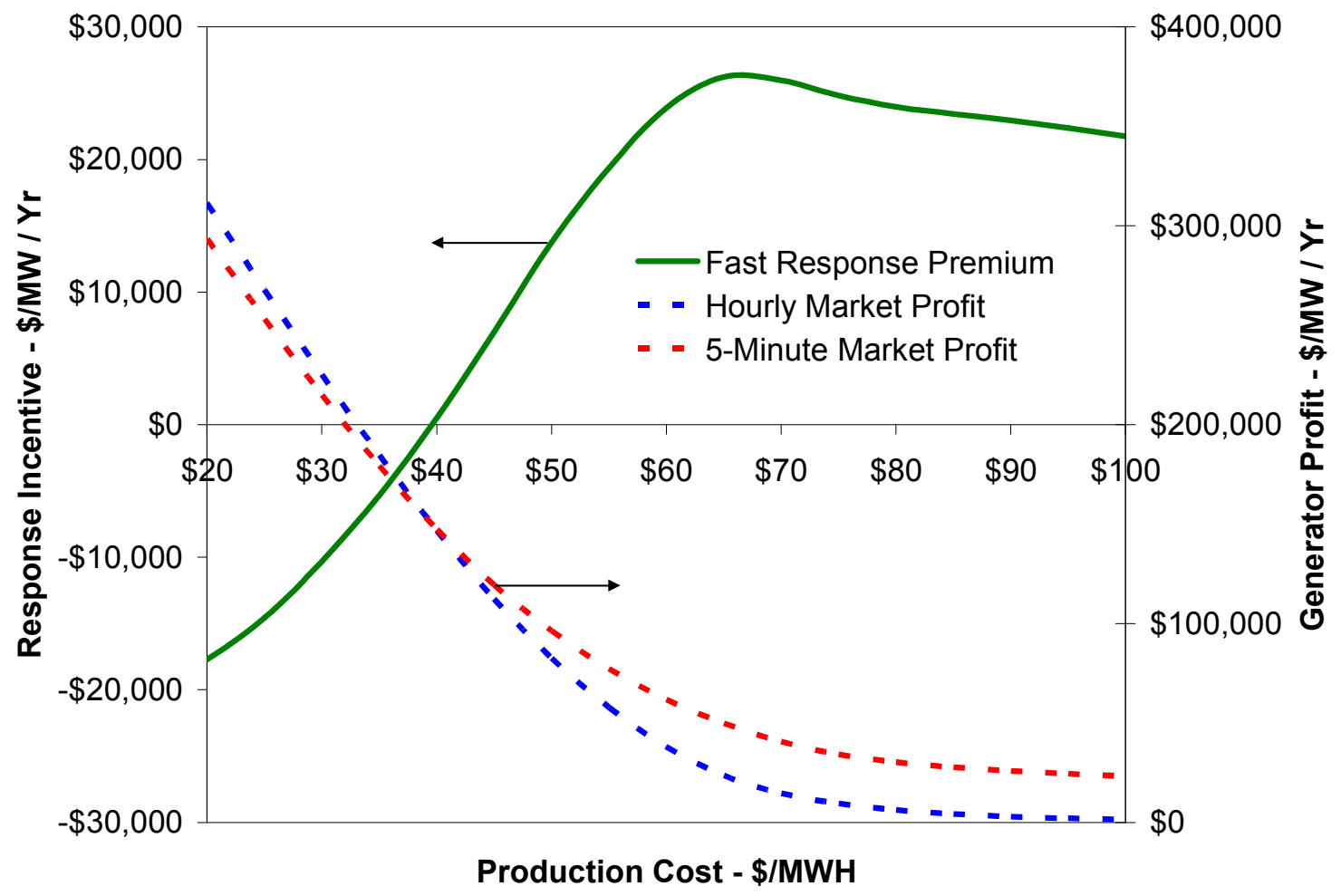

Figure 14 - Price data from NYISO 5-minute and hourly 2006 markets shows that generators with production costs around $\$ 40 / \mathrm{MWh}$ have an incentive to respond.

The net result is that regions that operate sub-hourly energy markets inherently provide economic incentives to specific generators to voluntarily provide intra-hour response and they can do this at no added cost. While minute-to-minute regulation is inherently an expensive ancillary service, intra-hour load following need not be.

\section{Implications for Wind Integration Studies}

There are two main implications for our analysis of wind integration studies. The first implication is that, depending on the generator characteristics and wind penetration, the load following impact of wind will depend on whether there is sufficient ramping capability in the energy units (and whether the market structure provides access to that

\footnotetext{
${ }^{3}$ The price where the response incentive starts is higher at locations with losses and congestion costs, but the concept is the same.
} 
capability). The second implication is that integration studies may incorrectly define the no-wind case that is compared to the wind case. We discuss each of these below.

\section{How does Wind Affect Load Following?}

Over the past several years there has been increasing interest and effort in performing wind integration studies. The methods and assumptions of these studies are similar, and one of the challenges is to define a suitable base case with no wind so that the wind impacts and integration cost can be meaningfully compared.

In several studies, particularly those involving large BAs, the load following impact of wind integration is zero or small. Table 1 is adapted from Smith et al (2007, "Best Practices in Grid Integration of Variable Wind Power: Summary of Recent US Case Study Results and Mitigation Measures" presented at the European Wind Energy Conference, Milan, Italy, May 2007). For these studies, the energy market or economic dispatch stack provided enough maneuverability so that modifications to the least-cost or market dispatch to cover ramps were not necessary. We have shown that if sufficient ramping capability is available from units on the margin of the energy market, then there is no additional need for a ramping service-it is provided as a by-product of the energy market.

Table 1 - Integration cost studies often find no load-following cost impact of wind.

\begin{tabular}{|c|c|c|c|c|c|c|}
\hline Date & Study & Penetration & $\begin{array}{c}\text { Regulation } \\
\text { Cost }\end{array}$ & $\begin{array}{c}\text { Unit } \\
\text { Commitment }\end{array}$ & $\begin{array}{c}\text { Gas } \\
\text { Supply } \\
\text { Cost }\end{array}$ & $\begin{array}{c}\text { Total } \\
\text { Operating } \\
\text { Cost Impact }\end{array}$ \\
\hline Nov 06 & MN/MISO & $\begin{array}{c}35 \% \text { capacity } \\
25 \% \text { energy }\end{array}$ & $\$ 0.15$ & $\$ 4.26$ & na & $\$ 4.41$ \\
\hline Apr 06 & Xcel-PSCo & $15 \%$ capacity & $\$ 0.20$ & $\$ 3.32$ & $\$ 1.45$ & $\$ 4.97$ \\
\hline Jun 06 & CA RPS Multi-yr & $4 \%$ capacity & $\$ 0.45$ & na & na & $\$ 0.45$ \\
\hline Feb 07 & GE/Pier/CAIAP & $20 \%$ capacity & $\$ 0-\$ 0.69$ & na & na & $\$ 0-\$ 0.69$ \\
\hline
\end{tabular}

\section{What Is The Relevant No-Wind Case For Integration Studies?}

Our analysis also suggests that it is critical to carefully define the base case for wind integration studies. The critical issue is to separate and isolate the wind integration cost from the value of the energy that wind produces. One common technique that is used to assess wind integration cost uses a hypothetical generator that produces the same energy as the wind plant, but delivers this energy as a flat block. The intent of this technique is to focus on wind's impact on variability and uncertainty. Because the flat block is neither variable nor uncertain, this is an often-used base case that is compared to the wind case to determine the integration cost of wind. In systems that have the opportunity to sell excess energy, this approach may overstate wind's integration cost if energy sales are not carefully defined.

Figure 8 illustrates wind serving load within the host BA, discussed above. The figure shows the increased energy sales that are made possible by wind, ignoring for the moment any wind forecast errors or the impacts of those errors on prospective transactions. Figure 15 is based on Figure 8, and shows how the wind energy might be converted into the flat block of energy for the comparison case, and shows the 
corresponding energy sale as the broken lines, one indicating wind generation as a flat block, and the other showing the additional sales the flat block would make possible.

Within Figure 15, we now have three distinct cases: (a) no wind, (b) actual wind, and (c) flat-equivalent wind. The question is which case, (a) or (c), should be used as the reference case to analyze wind integration impacts?

If case (a) is used as the reference case, the additional variability and uncertainty that wind brings in (b) is accounted for. The additional sales that wind makes possible are valued as-delivered. In our simple example, the wind energy is delivered at a time when energy prices are likely lower than prices later in the day. As pointed out in Figure 9, it is unlikely that all of the wind energy can be sold firm, even with fast energy markets. Instead, some of the wind energy may be sold either as non-firm or as part of imbalance settlements, depending on the market structure. In any analysis of wind impacts, it is important to define what wind is compared to. In this example, wind is compared to the displaced unit or units, which will back down by the amount of the wind energy if no additional sales are possible.

If case (c) is used as the reference case, the wind plant is penalized because it may provide energy during times when energy prices or marginal dispatch costs are low, and does not provide much energy when energy prices or marginal dispatch costs are high. In addition, the flat block is known in advance and can be sold in its entirety as firm energy. Because some of the wind will be sold as non-firm or in the imbalance market, there will likely be a differential in the revenue received when we compare cases (b) and (c) that arise because of the timing of wind and the level of confidence applied to the wind forecast. A flat block of energy is not the alternative to the with-wind case; the flat block is simply not available.

In our view, case (c), which compares wind to a flat block, captures a combination of integration cost and value of the wind compared to base-load generation. The cost impact is captured because wind brings additional variability and uncertainty compared to the flat block case; however, the differential in energy sales that can be realized because of the timing and predictability of the energy are differences in value, not cost.

In cases when wind is brought in to offset energy production from thermal units, saving fuel and reducing emissions, the relevant comparison case would be the no-wind case. In cases where wind is being compared to other potential types of generation, the specific alternative generation could be used as the comparison case, but we think it is important to recognize the difference between integration cost and value.

There may be ways to isolate cost from value. One approach would be to create flat blocks of wind-equivalent energy and separate them based on periods of high or low energy value. Some markets have defined heavy load hours and light load hours; this would help separate the value from cost. If market prices are available for markets that run hourly, that would further enhance this separation. 


\section{Wind Serves Internal BA Load}

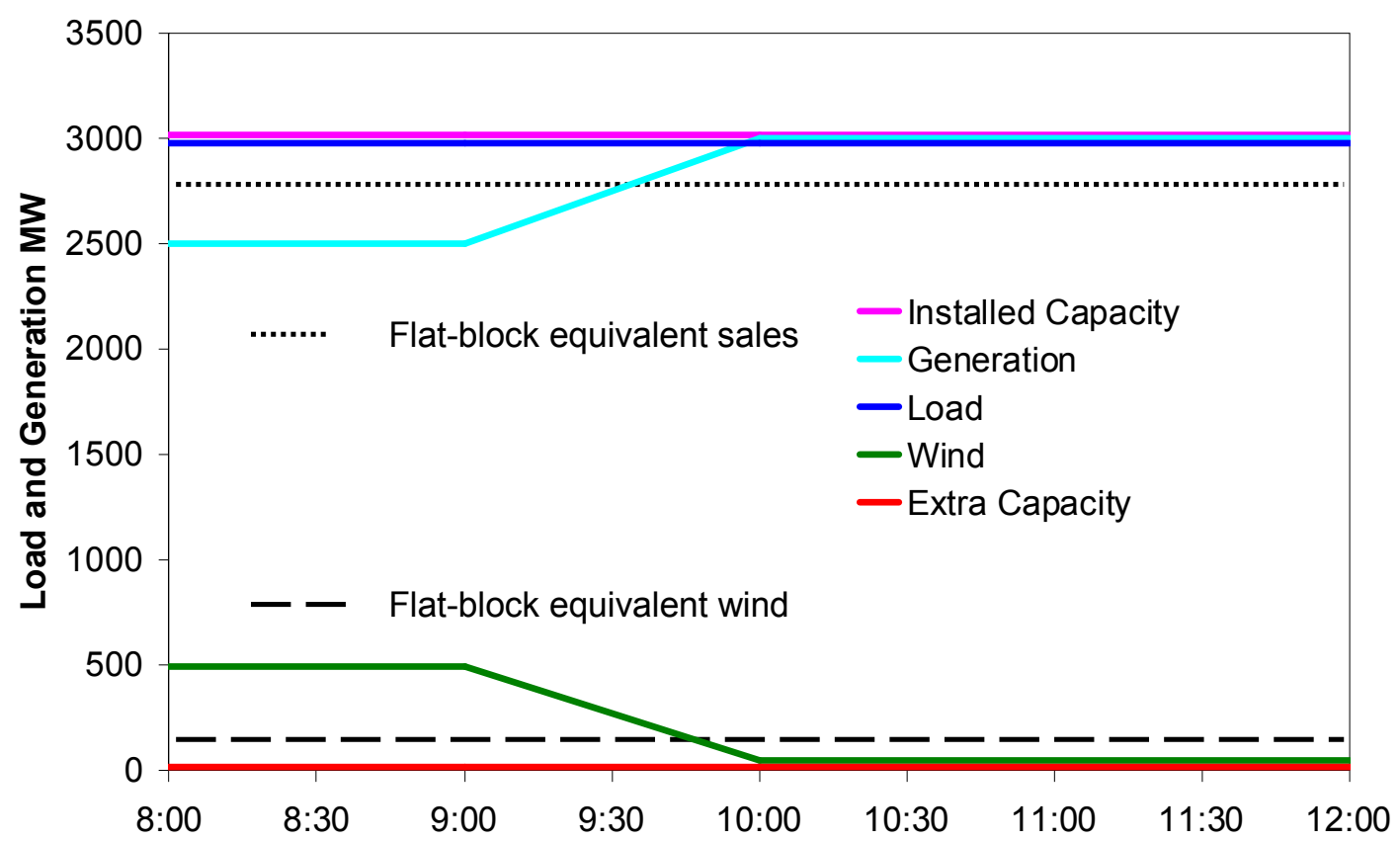

Figure 15 - Example of a flat-block equivalent benchmark for wind integration studies that increases energy sales.

\section{Summary and Conclusions}

When wind is serving load within the host BA, wind does not increase the requirements for capacity in that balancing area. Instead, existing capacity is used in a different way and on a different schedule. Wind may increase the need for fast ramping from conventional units, but this ramping is supplied from capacity that already exists. When wind serves load outside the host BA, there may be additional capacity required by the host to hold the wind's schedule until the beginning of the next market period or scheduling period. If generation is only dispatched hourly, this capacity requirement could potentially be significant. However, the capacity requirement is an artifact of the scheduling restrictions and provides no physical value to anyone. The additional capacity requirement can be reduced or eliminated by a variety of means that include faster market periods, dynamical scheduling, or other bi-lateral arrangements.

When wind integration studies utilize a flat-block wind-equivalent benchmark, care must be used to ensure that wind's value is not commingled with its integration cost. Because wind energy creates the opportunity for other units' energy to be sold, the revenue from 
this sale should be separately recognized. It may be appropriate to net this benefit against the cost of additional flexibility that is required to balance the system with significant levels of wind energy.

The increased load following that wind induces can often be supplied by fast energy markets. To participate in fast markets, generators must be able to position themselves so that they are physically able to sell the energy they have contracted for. This movement, or ramp, can help balance the system. When there is insufficient ramping capability in the economically dispatched units, quick-start generators may be required to run out of merit order so that the fast ramp can be covered until the slower intermediate units can respond. We also show that prices in the NYISO appear to properly encourage generators to respond to price signals in fast markets, thereby supplying the load following that is needed.

\section{Acknowledgments}

The authors thank Ken Dragoon, Renewable Northwest Project for helpful suggestions and discussion. 


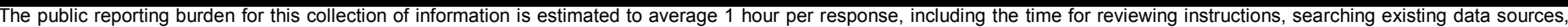

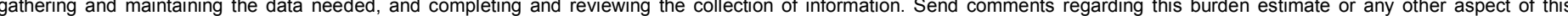

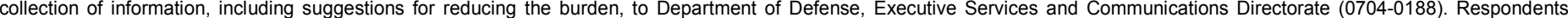

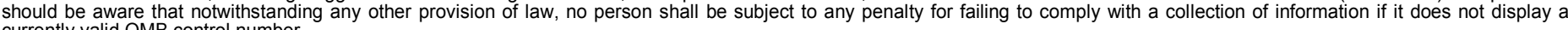
currently valid OMB control number.

PLEASE DO NOT RETURN YOUR FORM TO THE ABOVE ORGANIZATION

\section{REPORT DATE (DD-MM-YYYY) July 2008 \\ 2. REPORT TYPE \\ Technical Report}

4. TITLE AND SUBTITLE

Examination of Capacity and Ramping Impacts of Wind Energy on

Power Systems

\section{DATES COVERED (From - To)}

5a. CONTRACT NUMBER

DE-AC36-99-G010337

5b. GRANT NUMBER

5c. PROGRAM ELEMENT NUMBER

5d. PROJECT NUMBER

NREL/TP-500-42872

5e. TASK NUMBER

WER8.5001

5f. WORK UNIT NUMBER
7. PERFORMING ORGANIZATION NAME(S) AND ADDRESS(ES)

National Renewable Energy Laboratory

1617 Cole Blvd.

Golden, CO 80401-3393
8. PERFORMING ORGANIZATION REPORT NUMBER

NREL/TP-500-42872

9. SPONSORING/MONITORING AGENCY NAME(S) AND ADDRESS(ES)

10. SPONSOR/MONITOR'S ACRONYM(S) NREL

11. SPONSORING/MONITORING AGENCY REPORT NUMBER

\section{DISTRIBUTION AVAILABILITY STATEMENT}

National Technical Information Service

U.S. Department of Commerce

5285 Port Royal Road

Springfield, VA 22161

\section{SUPPLEMENTARY NOTES}

\section{ABSTRACT (Maximum 200 Words)}

When wind plants serve load within the balancing area, no additional capacity is required to integrate wind power into the system. We present some thought experiments to illustrate some implications for wind integration studies.

\section{SUBJECT TERMS}

Wind; integration; wind integration; scheduling; forecasts; electric utilities; ISO; RTO

\begin{tabular}{l}
\hline \multicolumn{3}{|l|}{ 16. SECURITY CLASSIFICATION OF: } \\
\begin{tabular}{|l|l|l|}
\hline a. REPORT & b. ABSTRACT & c. THIS PAGE \\
Unclassified & Unclassified & Unclassified \\
& & \\
\hline
\end{tabular}
\end{tabular}

17. LIMITATION
OF ABSTRACT
UL

18. NUMBER
OF PAGES

19a. NAME OF RESPONSIBLE PERSON

19b. TELEPONE NUMBER (Include area code) 